EGU2020-19205

https://doi.org/10.5194/egusphere-egu2020-19205

EGU General Assembly 2020

(c) Author(s) 2020. This work is distributed under

the Creative Commons Attribution 4.0 License.

\title{
Seismicity cluster below the Moho indicates thrust faulting in the central Ligurian Basin
}

\author{
Martin Thorwart ${ }^{1}$, Anke Dannowski ${ }^{2}$, Heidrun Kopp ${ }^{2}$, Dietrich Lange ${ }^{2}$, Wayne Crawford ${ }^{3}$, Anne \\ Paul $^{4}$, and Felix Noah Wolf ${ }^{2}$ \\ ${ }^{1}$ University of Kiel, Institute of Geosciences, Kiel, Germany (martin.thorwart@ifg.uni-kiel.de) \\ ${ }^{2}$ GEOMAR Helmholtz Centre for Ocean Research Kiel, Germany \\ ${ }^{3}$ Institut de Physique du Globe de Paris, France \\ ${ }^{4}$ Institut des Sciences de la Terre (ISTerre) CNRS \& Université Grenoble Alpes, France
}

The Alpine orogen and the Apennines system are part of the complex tectonic settings in the Mediterranean Sea caused by the convergence between Africa and Eurasia. Between $30 \mathrm{Ma}$ and 15 $\mathrm{Ma}$, the Calabrian Subduction retreated in southeast direction pulling Corsica and Sardinia away from the Eurasian continent. In this extensional setting, the Ligurian Sea was formed as a back-arc basin. The rifting jumped 15 MA ago to the Tyrrhenian Sea leaving Corsica and Sardinia in a stable position relative to Eurasia as observed by GPS measurements.

Within the framework of the AlpArray research initiative and its German component "4D Mountain building" (SPP2017 4D-MB) a long-term experiment was conducted in the Ligurian sea to investigate the lithosphere structure and the seismicity in the Ligurian basin. The passive seismic network was operated by France and Germany and consisted of 29 broad-band ocean bottom stations. It was in operation between June 2017 and February 2018. At the end of the experiment two active seismic profiles were conducted additionally.

A cluster of 15 events with magnitudes lower than 2.5 occurred in the centre of the Ligurian Basin. The earthquakes are located at a depth of $20 \mathrm{~km}$ to $35 \mathrm{~km}$, i.e. $10-25 \mathrm{~km}$ below the Moho. The cluster was not continuously active but had several active periods which lasted between 2 and 5 days.

A fault plane solution could be determined of the larger events in the cluster. The mechanism is a thrust faulting. Smaller events should have a similar mechanism due to the highly coherent waveforms. A similar mechanism was observed for the $\mathrm{Mw}=4.9$ earthquake on 07.07.2011 which occurred $50 \mathrm{~km}$ east of the cluster. Both solutions show a SW-NE striking, northwest dipping fault plane. This indicates a convergence in NW-SE direction between Corsica and Eurasia. 